Kazakhstan

\title{
Values of the Youth of Kazakhstan
}

DOI: 10.15804/tner.2018.52.2.11

\begin{abstract}
This article is written on the basis of sociological research conducted by the Research center of the Republic of Kazakhstan "Youth" for the preparation of the annual National Report "Youth of the Republic of Kazakhstan". The authors of this article were the authors of the section "Values of Youth" and "Readiness of the youth of Kazakhstan for migration". This article reflects on the results of the research, the "Values of the Youth of Kazakhstan" section. The National report of the Republic of Kazakhstan "Youth of Kazakhstan 2017" does not include all the findings and conclusions of the research group, so this article contains the most comprehensive data on the issues under study, namely - the values of the youth of Kazakhstan in dynamics and various correlations: age values, region (oblast) values, gender values, the level of education values, religion values, employment values, city or village values.
\end{abstract}

\section{Introduction}

Analyzing the values of the Kazakh youth, we proceed from the following common definitions of the concept of "value".

The value here also acts as a characteristic of the subject or phenomenon, indicating the recognition of its importance in the scale of values of young people. Values are also considered in the philosophical aspect, pointing to the personal, social and cultural significance of certain objects and phenomena in the life and consciousness of young people. We do not avoid including values of the economic 
aspect in the considered concept, namely the value as a synonym of the concept of "consumer value", i.e., the importance, usefulness of the subject for the studied consumer, namely youth.

The study of young people's system of values is the most important, as the future of independent and sovereign Kazakhstan depends on the younger generation, on their consciousness, the values that prevail in their understanding of the world ${ }^{1}$.

\section{Research Methodology}

Analysis of the available statistical information on various fields related to the youth of Kazakhstan has demonstrated the existence of a problems in its collection and systematization. First, the discrepancy between the age groups of young people in the statistical ranks of different spheres was revealed. Second, there was a difficulty in gathering up-to-date statistical information. In the preparation of the national report of the Republic of Kazakhstan "Youth of Kazakhstan 2017", and the sections specified by us, the specialists of the research center "Youth" used official statistics, data of the state bodies of the national and local levels, information received from national companies of Kazakhstan, youth organizations, scientific, informational and analytical materials, data of sociological research.

When preparing this article and the section of the same name in the National report, the results of mass sociological surveys of the research center "Youth" were shown, which were commissioned by the order of the Ministry of Education and Science of the Republic of Kazakhstan in 2017, are given. The volume of the Republican sample for each study comprised 2000 young respondents. The study used comparative, comparative-historical, empirical, systemic, sociological methods and content analysis.

\section{Research Results}

Among age cohorts (cf. Table 1), the age group from 14 to 18 years (73.5\%) consider themselves the happiest. This is followed by the young people aged $19-23(67.7 \%)$, and, further, these sensations are on the decline $-62.1 \%$ of the

1 The administrative division of Kazakhstan includes 14 regions and 2 cities of republican significance. http://www.akorda.kz/en/republic_of_kazakhstan/kazakhstan. 
24-29-year-old respondents. The young people aged 24-29 consider themselves "somewhat happy" (Table 1).

Table 1. Self-identification of the Kazakh youth by the "happy-unhappy" dichotomy

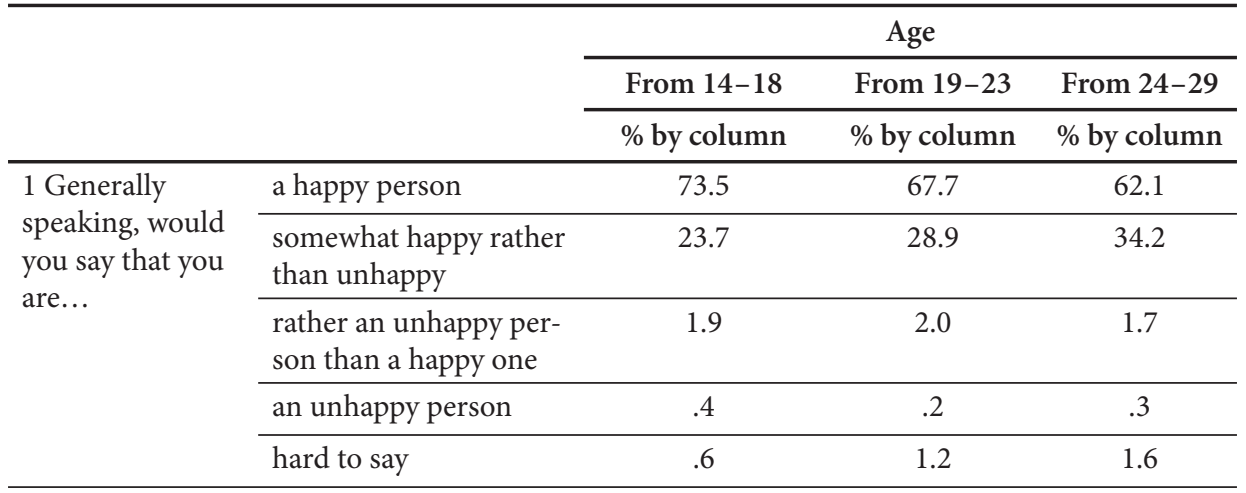

The young people in the age group $14-18$ and $19-23$ years $(23.7 \%$ and $28.9 \%$ respectively) identify themselves as "somewhat happy" rather than unhappy.

Less than a half of the percentage of young people among all the age groups identified themselves as unhappy. Thus, the Kazakh youth has a rather optimistic mood in the identification of themselves in the "happy-unhappy person" dichotomy.

The girls are more optimistic, the percentage is higher among them (68.2\%) than among the boys (64.9\%) (cf. Table 2).

Table 2. Self-identification of the Kazakh youth by the "happy-unhappy" dichotomy. Correlation by gender

\begin{tabular}{|c|c|c|c|}
\hline & & \multicolumn{2}{|c|}{ Gender } \\
\hline & & Male & Female \\
\hline & & $\%$ by column & $\%$ by column \\
\hline \multirow{5}{*}{$\begin{array}{l}\text { 1. Generally } \\
\text { speaking, } \\
\text { would you } \\
\text { say that you } \\
\text { are... }\end{array}$} & a happy person & 64.9 & 68.2 \\
\hline & somewhat happy rather than unhappy & 31.1 & 29.1 \\
\hline & rather an unhappy person than a happy one & 1.9 & 1.8 \\
\hline & an unhappy person & .4 & .2 \\
\hline & hard to say & 1.8 & .7 \\
\hline
\end{tabular}


It is important to note that studying youth feel much happier $(75.6 \%)$ than non-students $(63.3 \%)$ or working youth $(60.6 \%)$.

The hierarchy of values in the life of young people is as follows (average values) (cf. Table 3):

Table 3. Values of the Kazakh youth. "Values-age groups" correlations.

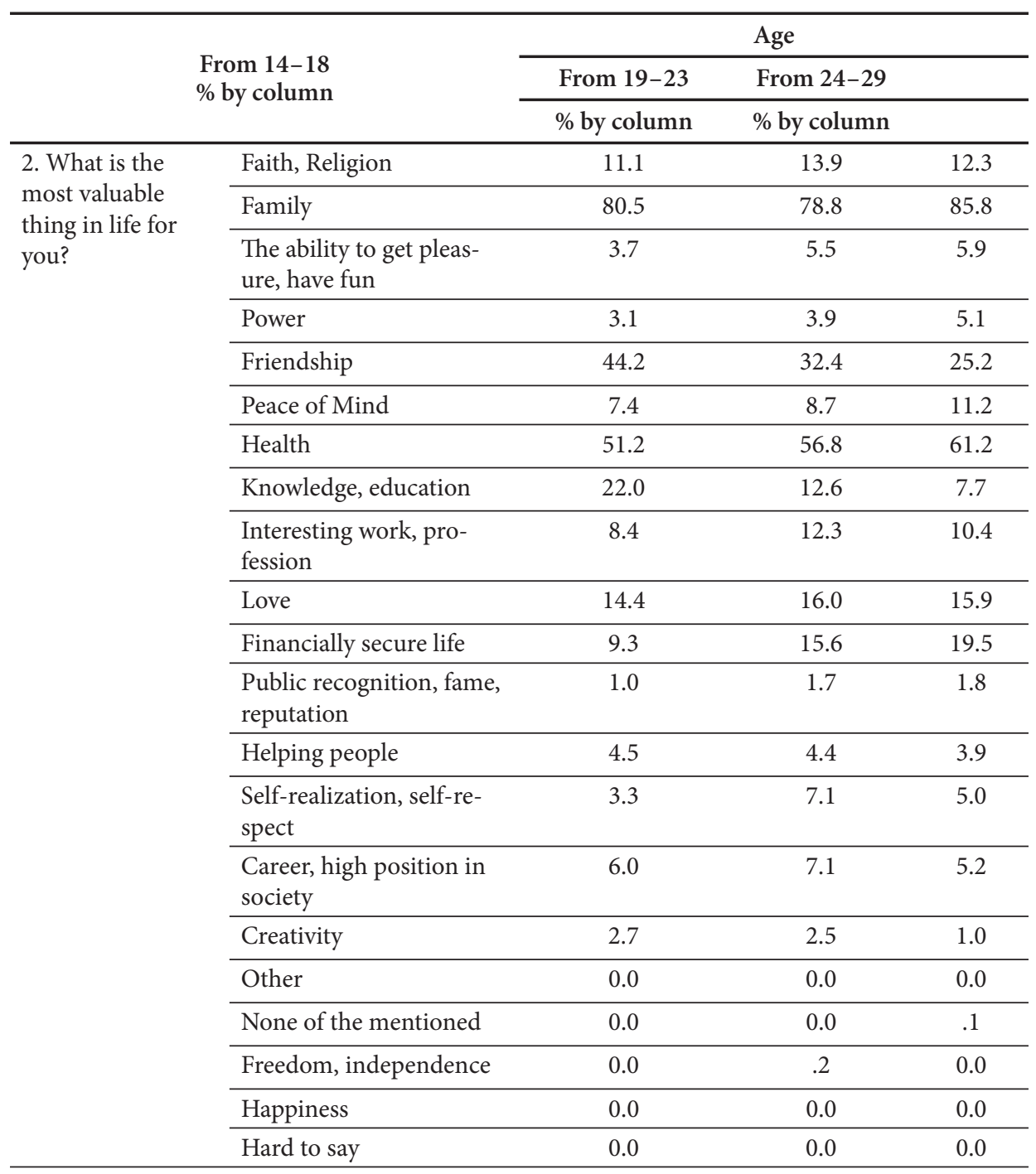


At the same time, the values of freedom, independence, happiness mean little to the Kazakh youth, gaining a maximum of 0.2 . Thus, the value of freedom and independence, understood both as personal and as a whole, of one's country, the state, does not have a pronounced priority. As can be seen, these spiritual values are not significant enough, which is an indirect manifestation of a certain conformity of the youth.

It should be noted that the older the youth, the more family and health values, as the most important two pillars, play a role in life. Among all the age groups, social acceptance plays a less important role.

In the ranking of values, the Kazakh youth considers family as an absolute value among all the three age groups. Moreover, there is a tendency: the older and more mature young people are, the greater is the importance attached to the institution of the family in their value hierarchy: $85.8 \%$ of the young aged $24-29$ years, $78.8 \%$ of those aged $19-23$ years, $80.5 \%$ of those aged 14 to 18 years. The family, according to almost $79 \%$ of the respondents, is responsible for the spiritual and moral education of Kazakh youth (to be kind, honest, responsible, etc.). At the same time, the role of the school, state bodies for the support and development of young people, religious institutions, and unions of peers is noted.

\section{Family is an absolute value for the young people, without exception, of all the regions of Kazakhstan}

Happiness in the category of value is absolutely not perceived by young people: none of the respondents attached importance to it, even in tenths. The values of career, high position in society, and financially secure life prevail over the desire of helping people. Ambitions of public recognition, fame, reputation, as an established opinion about self in society also occupy a negligible place in the youth's hierarchy of values.

The high value given by the young respondents to such categories as friendship and love testifies to the fact that the positive, romantic model of interpersonal relations dominates in the youth environment. Accordingly, the model of future family relations is focused more on positive experiences and intimate and personal relationships. Based on the results of the survey, we can draw a cautious conclusion that modern marriages among young people in Kazakhstan in most cases are based mainly on the free choice of a spouse, on their own feelings and personal decision. In particular, the motive of "the desire to be together with a loved one" absolutely prevails among the surveyed youth of all the age cohorts (69\%) over the 
"advice and insistence of parents" (11\%) and "the desire to have children" (10\%), to start a family. However, it should be noted that childishness (or child-centered motives) as a motive for starting a family is second in the ranking of the youth, but higher than the "insistence of parents" and the desire to "be like everyone else". Thus, the image of the future parent, educator, as an important integrative indicator of parent-child relations occupies an important place in the system of values of the Kazakh youth.

The results of the research clearly indicate an extremely high degree of importance of the family as an indispensable value. Moreover, it is possible to note the transformational nature of the development of the family institution in Kazakhstan, clearly showing the revival of traditional Kazakh family reproductive behavior with a priority focus on a large family (an average of three age cohorts $-10.3 \%$ ), against those who believe that the family should have no more than one child (3.4\%). Moreover, regardless of the number of planned children, the respondents point to the desired image of the family, in which grandparents live together with children and grandchildren. In fact, it is a multi-faceted (multi-generational) type of family, where three generations live under one roof: grandparents, their adult children and grandchildren.

Among goal-setting in life, the most important goal in life for the young men is material security (43.7\%), and this goal is updated with age. In the second place - being a good family man, and in the oldest age cohort of young people (24-29 years) is the most desirable image of the future (50.5\%), which means for them much more than material security (47.2\%).

For the representatives of the female half of the youth of all the age cohorts, the main goal in life is to be a good family person (44.9\%).

And without exception, in all the age cohorts, ideal family is a full family, where there are both parents.

It is worth noting that the number of those wishing to have a good family is much higher among the non-studying and non-working youth (59.2\%), which is most likely due to the way of stability in life associated with having a family of their own than among the working youth $(47.2 \%)$ and students $(35.4 \%)$. In the third place of the youth's vision of itself in the future, there is a professional in business, a good worker, and those most of all among the studying youth (34.4\%) and among those who do not study, do not work, but look for work (26.6\%), than among the those working (25.7\%) and not working, not studying and not looking for work (20.1\%).

For the young people of all the age groups of Kazakhstan, to be happy is an abstract and insignificant category, occupying the last place in the line of pref- 
erences, not even reaching $0.5 \%$. Also, the young people do not consider seeing the world and travelling as the main goal, apparently believing that becoming financially secure ( $1^{\text {st }}$ position), having a good family ( $2^{\text {nd }}$ position), being a professional $\left(3^{\text {rd }}\right)$, becoming a worthy citizen $\left(4^{\text {th }}\right)$, being famous, while maintaining the quality of an honest and principled person, a sense of happiness and the opportunity to travel will come together with all this.

The older the young people are, the less altruistic they are: helping people is not such an important value for the respondents.

The young people of Kazakhstan are focused on work as the basis of all their future achievements, believing that to achieve these goals it is necessary to work tirelessly. This is the opinion of the vast majority of the respondents, agreeing that "work is a vital need of a person, contributing to the development of their personality". It is logical, however, that the largest number of those who doubt that "work does not always contribute to success, the main thing in life is luck, good family and friendship ties" belongs among the non-studying, non-working and non-job-seeking youth (22.3\%).

The results of sociological research have shown the absolute dominant orientation of the young people to the patriarchal type of interactions between spouses.

The youth of Kazakhstan in most cases does not choose the egalitarian (partner) model of family relations, based on the recognition of equal rights and responsibilities of spouses, and is inclined towards the patriarchal type of interactions between spouses in the family, as demonstrated, e.g., by the European youth, where the results of similar studies indicate a high starting readiness of spouses for competition (struggle) for leadership and advocacy of individual interests. All the three age cohorts are in solidarity in the distribution of future/present role - playing roles in the family: the male - breadwinner, the female - keeper of the family hearth.

Table 4. Instrumental values. Values that the Kazakh youth wants to instill in their children

\begin{tabular}{lllll}
\hline & Independence, autonomy & $28.6 \%$ & $25.7 \%$ & $24.8 \%$ \\
\cline { 2 - 5 } Which qualities & Diligence & $66.3 \%$ & $65.5 \%$ & $69.6 \%$ \\
\cline { 2 - 5 } $\begin{array}{l}\text { do you think are } \\
\text { most important }\end{array}$ & Sense of responsibility & $42.4 \%$ & $38.7 \%$ & $40.8 \%$ \\
\cline { 2 - 5 } to raise a child? & Love for the home country & $38.1 \%$ & $38.7 \%$ & $37.5 \%$ \\
\cline { 2 - 5 } & $\begin{array}{l}\text { Respect for the traditions and cus- } \\
\text { toms of one's ethnic group }\end{array}$ & $13.4 \%$ & $18.8 \%$ & $16.2 \%$ \\
\hline
\end{tabular}


Mukhit-Ardager Sydyknazarov et al.

\begin{tabular}{|c|c|c|c|c|}
\hline \multirow{15}{*}{$\begin{array}{l}\text { Which qualities } \\
\text { do you think are } \\
\text { most important } \\
\text { to raise a child? }\end{array}$} & $\begin{array}{l}\text { Tolerance and respect towards } \\
\text { others }\end{array}$ & $21.2 \%$ & $22.2 \%$ & $20.8 \%$ \\
\hline & $\begin{array}{l}\text { Frugality and careful attitude to } \\
\text { money and things }\end{array}$ & $10.7 \%$ & $13.6 \%$ & $14.1 \%$ \\
\hline & Determination, perseverance & $14.0 \%$ & $18.0 \%$ & $17.3 \%$ \\
\hline & Religiosity & $4.3 \%$ & $5.4 \%$ & $5.2 \%$ \\
\hline & Unselfishness & $12.1 \%$ & $11.3 \%$ & $12.7 \%$ \\
\hline & Obedience & $9.9 \%$ & $12.8 \%$ & $9.2 \%$ \\
\hline & Other & $.2 \%$ & $0.0 \%$ & $0.0 \%$ \\
\hline & Courtesy, good behavior & $.2 \%$ & $0.0 \%$ & $0.0 \%$ \\
\hline & Savvy & $0.0 \%$ & $0.0 \%$ & $.1 \%$ \\
\hline & Pursuit of knowledge & $0.0 \%$ & $0.0 \%$ & $.2 \%$ \\
\hline & Honesty & $0.0 \%$ & $0.0 \%$ & $.1 \%$ \\
\hline & Sensitivity & $0.0 \%$ & $0.0 \%$ & $.1 \%$ \\
\hline & Financial literacy & $0.0 \%$ & $0.0 \%$ & $.1 \%$ \\
\hline & Decency & $0.0 \%$ & $0.0 \%$ & $0.0 \%$ \\
\hline & Hard to say & $.6 \%$ & $0.0 \%$ & $.9 \%$ \\
\hline
\end{tabular}

Of the instrumental values (Table 4), which they would like to instill in their future and current children, the young people choose the top five: diligence (on average $-67.1 \%$ in all the three age cohorts), sense of responsibility (40.6\%); love for the home country (38.1\%); independence and autonomy (26.4\%), tolerance and respect towards others $(21.4 \%)$.

The vast majority of the young people have knowledge about the official state symbols of Kazakhstan and their components, i.e., over $90 \%$.

The presence of "independence and autonomy" among the goals that they would like to instill in their future and current children is discordant with the recognition of independence as the least important value of the young people (under $0.2 \%$ ). This is a paradox: independence and freedom are not values for the interviewed youth- present and future parents, but they want to see it in their children.

Religion and faith occupy a definite place among the young people.

Faith, religion as a value among the interviewed youth are important after the family, health, friendship, knowledge and education, love, and financial security. And among the men, this index is higher (14.1\%) than in the female part of the respondents (10.9\%). 
Most of the respondents are practising believers, i.e., those who "sometimes" or "very rarely" perform religious rites. The number of believers "participating in the life of their religious communities, according to the following religious norms" (10\%) is lower than that of those who identify themselves as "believers, but not participating in religious practices" (43\%). At the same time, the share of those whom "religion helps in spiritual and moral education" is slightly larger (on average $40 \%$ ) than those who believe that "family, education and the state are more important in these processes" (on average 23\%). At the same time, it is paradoxical that the contemporary and future young parents do not give such a high, expected priority to the education of religiosity, as becomes apparent from numerous publications in print and electronic media devoted to the growth of religiosity among young people. The youth of Kyzylorda region (10.1\%), Almaty (6.3\%) pays the most attention to the education of religiosity in future generations. In other regions, this figure does not exceed $6 \%$.

What are the priority sources of information among the youth of the Republic of Kazakhstan?

The sources of news for the young people are (in descending order) - news releases on television (from $49 \%$ to $61.8 \%$ ), news websites (from $46.3 \%$ to $61.8 \%$ ), news releases on the radio ( $24 . \%$ to $39.1 \%)$.

The vast majority of the young people in Kazakhstan use the Internet daily $(82.3 \%)$. Only $3.4 \%$ of the respondents do not use the world wide web at all.

Social networks (from $84.6 \%, 87.7 \%$ and $82.6 \%$ respectively) are the undisputed leaders of views and sources of relevant information among the young people. The leaders among the social networks used by the youth in Kazakhstan are the following: WhatsApp holds the first place, then, Vkontakte, Instagram, Facebook are located on the popularity scale of the network. Moreover, when getting older, the 24- to 29-year-old respondents increase the tendency to exhibit, increasingly turning to Facebook (35.2\%). Snapchat and Twitter are also popular. So far the more active social networkers are the female respondents. $6 \%$ of the young people do not have social media accounts.

The situation is almost similar with the reading of printed and electronic newspapers and magazines: almost a third of the respondents refer to them during the week, and two-thirds have not used them. Moreover, regular publications are still read relatively more $(29.6 \%, 31.4 \%, 38.9 \%)$, than electronic ones $(23.3 \%, 25.2 \%, 31.1 \%)$.

The culture of reading among the young people in Kazakhstan is depressing: the number of those who have read, watched or listened to books during the last week, including electronic or online ones, is much smaller $(29.8 \%, 30.6 \%, 32.5 \%)$ than that of those who have not $(65 \%, 65.4 \%, 63.6 \%)$. 
Traditional libraries of all types and levels are consistently losing ground to frequent visits by young people. Print media still retain their predominant influence among the youth of Kazakhstan, though less than $50 \%$.

The results of the study revealed some dependence of certain aspects of the values on the respondent's gender.

Those who read fiction are mostly among the female part of the respondents (31.4\%) rather than male ones $(24.7 \%)$. Those who have not recently read fiction are mostly among the men (74.4\%) than women $(67.8 \%)$.

The musical preferences of the Kazakh youth are interesting. Most of all, using their gadgets the respondents listen to Western music, and this is most characteristic of the age group of 14-18 years (34.4\%), 19-23-year-olds and 24-29-year-olds' interest in Western music declines year by year (30.6\% and 25.5\% respectively), on the contrary, interest in Kazakh music (26.5\%) and classical music (14.8\%) increases. Modern Kazakh music is also an absolute favorite among the musical tastes of the young people: the older they are, the more interested they become in the national music $(26.5 \%)$. Interest in the roots of folk music $(8.6 \%)$ has also been growing steadily with age.

Cinema as a cultural object is the most visited place among the Kazakh youth. There are still some people who perceive an exhibition as a cultural event. There are more of those who have never visited an exhibition: in the context of regions those comprise $30 \%$ to $85 \%$. Visiting museums as historical, cultural and scientific centers is also of little interest to the young people: the number of those who have never visited is more than those who visit them once-twice a year. Almost onethird of the respondents of all the age groups also have never been to the theatre or attended concerts. There are about $60 \%$ of those who actively attend theatrical and concert productions (from once a month to 3-6 times a year).

Most respondents regularly visit places of worship: mosques and churches with varying degrees of regularity. So, once-twice a year they have been visited by $27 \%$ of the young people of all the three age cohorts, $14.8 \%$ visit them 3-6 times a year, $15.6 \%$ - once a month. Of the respondents, urban youth, with a slight advantage, visits mosques and churches more often than rural youth. $17.9 \%$ of the respondents in the cohort aged $24-29$ and $26.7 \%$ of the young people in the $14-19$ age group have never been to mosques/churches/synagogues.

A third of the urban youth, and over $40 \%$ of the rural youth in Kazakhstan, according to polls, have never attended a gym. $15.5 \%$ of the city youth, $8.7 \%$ of the rural youth, go to the gym once a week. The single youth goes to gyms and swimming pools more often than their family peers. 
Despite this, the vast majority of the respondents lead a healthy lifestyle: $86 \%$ do not smoke.

Urbanization as a process is gaining momentum. Most of the youth of Kazakhstan would like to see a multi-ethnic city as their place of residence. A third of the respondents would like to live in a city where the representatives of its predominant ethnic group live. $11 \%$ of the young people mentioned a village as their preferred place of residence, and the numbers of those wishing to live mainly in mono-ethnic or multi-ethnic villages are relatively the same.

\section{Discussion and Conclusion}

Value orientations and needs, as can be seen from the results of the survey, generally determine the life plans of young people. Despite the fact that the distribution of the respondents by age groups (cohorts) gave the opportunity to analyze changes in the value orientations of intergenerational interaction in the transition from one age group to another, from adolescence (14-18 years of age) to adulthood (24-29 years of age), the main results show an overall similar view on the hierarchy of values, solidarity positions in many value systems, bearing modern character, in terms of content approved and justifying the priority of the spiritual over the material.

As already stated, paternalistic expectations are not typical of the youth of Kazakhstan in general, but the most popular leader of social expectations are projects assisting in employment (54\%). Next, the following initiatives are in demand (in decreasing order): crime prevention, suicide prevention (29\%), projects for labor and social adaptation of young people in difficult situations, projects to support talented youth, projects for the prevention of religious extremism and terrorism. Paradoxically, the issues of housing, reduction of bank interest, free education, international mobility in the rating of the young respondents' expectations did not occupy a significant place, not exceeding $0.2 \%$.

However, the young people (over 60\%) believe that "the state should play an active role in society", although the proportion of those who do not believe in, or are indifferent towards the participation of the state in their lives all in all is more than a third of the respondents.

Competitiveness through computer literacy and knowledge of languages, the preservation of national history, maintaining a healthy lifestyle, the cult of knowledge - these are the four priorities that roused the most lively interest 
among the young. To sum up, we can say that the youth of Kazakhstan as a whole retains the continuity of the system of values, while based on the current political, economic, social and cultural context, new value guidelines have been developed. The decline in the economic standard of life, which resulted from the double devaluation of the national currency in 2015, the growth of religiosity among young people, and other factors also have an impact. The total number of values that are the property of young people is structured by them in certain systems, and their origins can be traced to culture, society and its institutions, and their influence - in all behavioral priorities and attitudes.

\section{References:}

Kaliev, T., Kaidarova, A., Ashimkhanova, D., Sydyknazarov, M. and other (2017). National Report "Youth of Kazakhstan - 2017". Astana: SIC Youth.

Kazakhstan Government (2016). The Concept of the State Youth Policy of the Republic of Kazakhstan until 2020 "Kazakhstan 2020: a way to the future (the second stage 2016-2020)", // http://adilet.zan.kz/kaz/docs/P1300000191.

Kazakhstan Government (2016). Action plan for the implementation of the Concept of the state youth policy of the Republic of Kazakhstan until 2020 "Kazakhstan 2020: a way to the future (second stage 2016-2020)".

Kaldybaeva, O., Kaliev, T., Nikolayeva O. (2017). Methodical recommendations "Influence of religion on the formation of the system of values of the Kazakh youth". Astana: SIC "Youth".

UNDP (2016). Overview. Human Development. Report (2016). Human Development for Everyone. By the United Nations Development Programme. From: http://hdr.undp.org/ sites/default/files/HDR2016_EN_Overview_Web.pdf. 